\title{
Proscribed drugs at the Olympic Games: permitted use and misuse (doping) by athletes
}

\author{
Ken Fitch
}

\begin{abstract}
Athletes have always sought to outperform their competitors and regrettably some have resorted to misuse of drugs or doping to achieve this. Stimulants were taken by the first Olympic athletes to be disqualified in 1972. Although undetectable until 1975, from the 1950s androgenic anabolic steroids were administered for increased strength and power followed in the 1990s by erythropoietin for enhanced endurance. Both are highly effective doping agents. As analytical science validated improved techniques to identify these drugs, Olympic athletes, including many medallists were caught and disqualified. When the International Olympic Committee (IOC) prohibited beta blockers (beneficial in shooting), diuretics (assist weight classified athletes) and glucocorticosteroids, some athletes with genuine medical conditions were denied legitimate medical therapy. To overcome this, in 1992 the IOC introduced a system known now as Therapeutic Use Exemption (TUE). This paper discusses Olympic athletes who have been known to dope at past Games and some medical indications and pitfalls in the TUE process.
\end{abstract}

KEY WORDS: Olympic games, doping, anabolic steroids, erythropoietin, therapeutic use

\section{Introduction}

The use of drugs to enhance performance at Olympic Games started during the Games in Ancient Greece, when hallucinogens from fungi and possibly strychnine were used by competitors. In 1904, during the third Olympiad of the modern era, Thomas Hicks, a 32-year-old athlete competing for the USA, although born in Birmingham, UK, won the marathon in oppressively hot conditions and was given strychnine (and brandy) during the race by his trainer. However, it was the death of a Danish cyclist at the 1960 Rome Olympics (he was alleged to have taken amphetamine) that provoked the International Olympic Committee (IOC) to establish a Medical Commission (IOCMC). Its first task was to compile, in 1967, The List, which was a list of prohibited substances and methods. ${ }^{1}$ Initially, only stimulants and narcotics, drugs that could be identified by urine testing, were prohibited. From 1968, athletes were required to provide urine samples (termed 'doping controls') at Olympic Games and those with prohibited drugs in their urine were disqualified. Generally, an additional sanction was imposed by their

K. Fitch, professor, school sports science, exercise and health, University of Western Australia; member, Medical Commission of the International Olympic Committee, Chair of its Therapeutic Use Exemption Committee sport. As analytical science improved and with the known misuse of drugs and doping methods by athletes to improve performance, additional classes of drug were added to The List, sometimes before a validated test to confirm their presence had been identified.

Principally, drugs were prohibited because of their capacity to enhance performance. In 2004, the World Anti-Doping Agency (WADA) assumed responsibility for The List from the IOC-MC. Currently WADA have three criteria for prohibiting a drug: if it enhances sport performance; if it would be harmful to health if withheld; or if it is against the spirit of sport. Two of the three criteria are necessary to include a substance or method on The List. Decisions in $1985-1988$ by the IOC-MC to prohibit glucocorticosteroids, diuretics and beta blockers were a catalyst for what have become known as Therapeutic Use Exemptions (TUE); that is, allowing athletes to administer prohibited drugs for genuine medical conditions and still compete. Such approvals are provided by authorised TUE Committees (TUEC), of which, the TUEC of the IOC, which has operated since 1992, was a pioneer. ${ }^{1}$ Today, all International Federations and most major countries have a TUEC. The three criteria that must be met to grant a TUE are:

- the athlete would experience significant impairment to their health if the medication was withheld;

- the prohibited substance would not increase the athlete's performance other than from restoring their health to normality;

- the athlete could not use a permitted alternative. ${ }^{2}$

In this article, I review some of the classes of prohibited substances and methods, and their probable effects on sports performance, and discuss examples of their known misuse by Olympic athletes. I also examine specific aspects of the concept of athletes obtaining approval to take prohibited drugs and still compete at major sports events, with emphasis on the Olympic Games.

\section{Stimulants}

Stimulants, which have been used in sport since the ancient Olympic Games and were involved in the deaths of cyclists at the 1960 Olympics and during the 1967 Tour de France, have been prohibited 'in-competition' at Olympic Games since 1968. All seven athletes who were sanctioned at the 1972 Munich Olympics, four of whom won medals, took a stimulant, Since then, between one and three athletes have been detected to be using prohibited stimulants at most subsequent Summer Olympic Games. 
Pseudoephedrine, which was removed from The List in 2004, was reinstated in 2010 with a urinary threshold of $150 \mu \mathrm{g} / \mathrm{ml}$ because of evidence of misuse by athletes and recent confirmation that it could improve running performance. ${ }^{3}$

Only recently have TUEs for stimulants been approved for attention deficit (hyperactive) disorder (ADD and ADHD) and narcolepsy in adult athletes, including Olympic athletes. Stringent conditions must be met and the opinion of two independent consultants is essential to approve stimulant medication to manage ADD and/or ADHD in adults. Many adult athletes with $\mathrm{ADD}$ and/or ADHD have had the condition since childhood, but frequently have either not received a proper diagnosis and/or been treated with prohibited stimulants, customarily either dexamphetamine or methylphenidate. To approve use of modafinil (also prohibited) or other stimulants for narcolepsy, the opinion of a consultant physician in sleep medicine plus a comprehensive investigation, including a positive multiple sleep latency test, are necessary. In doubtful cases, the TUEC should seek the advice of an expert referee.

\section{Beta blockers}

Beta blockers are prohibited only in certain sports because of their anti-tremor and, perhaps to a lesser degree, anti-anxiety effects. Before the 1984 Games in Los Angeles, the IOC-MC, aware that some athletes were taking beta blockers to improve performance in shooting events, demanded a medical certificate to justify their use. 'Medical certificates' were submitted by 18 athletes, who had won nine medals between them in either shooting or modern pentathlon. All were taking propranolol. In 1985, the IOC-MC reacted by prohibiting beta blockers in sports in which performance might be enhanced. In 1986, a $13.4 \%$ improvement in pistol shooting performance was demonstrated in a double-blind study after the participants had taken metoprolol 150 mg. ${ }^{4}$

Subsequently, one athlete in the modern pentathlon was sanctioned in 1988 for using propranolol; as a result, and partly to counteract this, modern pentathlon changed its competition to stage all five sports on the same day. Hence, the performancereducing effects of beta-blockade in the running and swimming competitions more than counter balance any benefit in shooting performance. At Beijing 2008, one pistol shooter won silver and bronze medals but was disqualified because of his misuse of propranolol. For London 2012, only shooting and archery will prohibit beta blockers. ${ }^{5}$

TUEs for beta blockers, which are necessary only in those sports that prohibit them, are approved predominately for major cardiac conditions. Thus, cardioselective beta blockers, which are believed to be less beneficial in reducing tremor compared with propranolol, are prescribed. Nevertheless, approval is rarely, if ever granted, for their use during shooting competitions. Other indications for beta blockers, including essential tremor, hypertension and migraine, should not be approved for use in sport; instead, permitted alternatives should be prescribed.

\section{Diuretics}

Diuretics were prohibited in 1985 because of concerns that the resultant urinary dilution would enable athletes using prohibited drugs, especially androgenic anabolic steroids (AAS), to escape detection. Although still considered a factor by WADA, most laboratory directors do not currently hold such concerns. This is because the greatly enhanced analytical hardware and software provide improved detection and should enable identification of prohibited substances from the resultant increased volume of urine despite a low specific gravity. However, the most important reason for prohibiting diuretics is for weight-classified athletes, because diuretics have the capacity to enable an athlete to compete in a lower weight category. This is tantamount to cheating. Since 1988, 11 athletes, all taking furosemide, have been disqualified at Olympic Summer Games, all but one in weight-classified sports, with weightlifting being the most common.

A TUE for a diuretic can never be approved for any athlete in a sport with weight categories, which includes all Olympic combat sports. Polycystic ovary syndrome managed with spironolactone is a relatively common condition in elite female athletes. Hypertension is occasionally encountered in elite athletes and requests for a diuretic, usually in combination with, and to augment the effect of, either an angiotensin-converting enzyme (ACE) inhibitor or an angiotensin II receptor antagonist, (both are permitted in sport) are approved. Renal disorders have also been encountered in Olympic athletes, necessitating therapy with a diuretic.

\section{Glucocorticosteroids}

Glucocorticosteroids (GCS) have posed most problems for athlete treatment since being prohibited by systemic use (ie oral, intramuscular, intravenous and rectal administration) but only in-competition. This occurred because of alleged misuse of GCS by cyclists and other athletes for their stimulant and euphoric adverse effects. Several double-blind studies have examined the effect of GCS on performance, with variable outcomes, and were recently reviewed. ${ }^{6}$ Although no significant improvement in exercise performance was demonstrated after acute pre-exercise ingestion of prednisolone, a significant improvement might result after a week of high-dose oral GCS. ${ }^{7}$ Conditions encountered at Olympic Games that necessitate athletes requiring systemic GCS either during or in close proximity to competition include inflammatory bowel disease, prevalent in elite athletes, acute severe asthma, anaphylaxis and the occasional elite athlete with adrenogenital syndrome and/or Addison's disease. With sound medical documentation, the use of GCS to treat these conditions is approved. Being prohibited only in-competition has more relevance at the Olympics because, unlike other major competitions, in-competition at the Games starts when the Olympic Village opens. Thus, for London 2012, in-competition will be 16 July to 12 August 2012. To date, no athlete has been disqualified at an Olympic Games for misuse of GCS, partly 
because of the difficulty of distinguishing analytically between prohibited systemic use from permitted administration by local injections and topical use.

\section{'Blood doping'}

Currently, 'blood doping' is considered by most to be a term describing several drugs and/or methods used to alter blood parameters and enhance performance, especially in endurance events. Initially, blood doping was described as withdrawing an athlete's blood, storing it and, weeks later, re-infusing it precompetition, which could improve maximal aerobic capacity $\left(\mathrm{VO}_{2 \max }\right)$ by approximately $9 \%{ }^{8}$ Some athletes at the Olympic Summer Games between 1972 and 1984 later admitted using this method to improve their performance, including members of the US cycling team in Los Angeles 1984. ${ }^{9}$ Hence, in 1985, blood doping was prohibited by the IOC-MC. In 1989, when erythropoietin (EPO) had been marketed, similar (approximately 10\%) improvements in $\mathrm{VO}_{2 \max }$ were reported after EPO administration. ${ }^{10}$ When Olympic athletes began to use EPO is conjecture but, at the 2002 Salt Lake City Winter Games, three cross-country skiers who won a total of eight medals, six of which were gold, were sanctioned when darbepoetin, a second-generation EPO, was found in their urine. Five athletes, including two medallists, who competed in the 2008 Beijing Olympics were later disqualified from the Games for using continuous erythropoietin receptor activator (CERA), a long-acting third-generation EPO.

A 2004 Olympic cycling gold medallist was found to have doped with non-autologous blood. However, incorrect storage prevented confirmation of the B sample and he could not be sanctioned. He was target tested at the Tour of Spain, which followed soon after, when his transfusion was confirmed and, retro-actively, he was disqualified from the 2004 Athens Games and forfeited his gold medal.

No TUE for blood doping can be approved but if an EPO preparation was deemed medically essential for major renal disease, the strict criteria of various renal authorities on managing the anaemia of patients with renal failure on dialysis must be met; that is, the haemoglobin should not exceed $120 \mathrm{~g} / \mathrm{l}$ unless certified as safe by the treating renal physician; in athletes, the haemoglobin should never exceed $140 \mathrm{~g} / \mathrm{l}$ in males and $130 \mathrm{~g} / \mathrm{l}$ in females.

\section{Androgenic anabolic steroids}

The use of androgenic anabolic steroids (AAS) by athletes, including Olympic competitors, started during the 1950s, ${ }^{11}$ before any test to identify AAS had been developed; and a discus competitor at the 1972 Munich Games reported their widespread misuse by power athletes. ${ }^{12}$ However, the national system of scientific doping, initially with an oral AAS and later testosterone $(\mathrm{T})$, practiced by the East Germans mainly on female athletes between 1972 and 1988, was most successful. ${ }^{13}$ In the three Olympic Summer Games before its introduction, East Germany won only $56 \%$ of the number of medals won by West Germany; by contrast, at the three Games in which widespread doping with AAS occurred, East Germany won 217\% of the number of medals won by West Germany. ${ }^{13}$

Ground-breaking research by Brooks and colleagues at St Thomas' Hospital, London that identified AAS by radio-immunoassays, ${ }^{14}$ enabled the IOC-MC to prohibit AAS before the 1976 Montreal Games, at which seven weightlifters (three medallists) and a female discus thrower were disqualified for AAS use. At each subsequent Summer Games, except Moscow 1980, two or more athletes (including several medallists) have been disqualified for using anabolic agents. The most notable AAS cheat has been Ben Johnson, who had stanozolol in his urine after winning gold in the $100 \mathrm{~m}$ in Seoul 1988.

Although the East Germans had unpublished evidence of the effectiveness of AAS as doping agents, it was not until 1996 that any study scientifically demonstrated the increased muscle bulk and strength resulting from supraphysiological doses of T. ${ }^{15}$ As analytical science steadily improved, detection of AAS became easier, but currently remains a challenge because clandestine laboratories, especially but not only, those in China, are producing designer AAS. Detecting doping with $\mathrm{T}$ remains a challenge, because of the need to distinguish exogenously administered $\mathrm{T}$ from that produced endogenously. The initial method was based on elevation of the urinary testosterone/epitestosterone (T/E) ratio above 6 rather than the normal, unity in Caucasians. ${ }^{1}$ However, the T/E ratio posed as many difficulties as solutions and was demonstrated to be flawed because of wide ethnic differences resulting, in part, to deletion polymorphism of the UGT2B17 gene. ${ }^{16}$ Isotope ratio mass spectrometry (IRMS) has solved these problems and is now accepted as the gold standard. ${ }^{17}$

TUEs for $\mathrm{T}$ were some of the first exemptions ever approved nationally during the 1980 s for males without testes, ${ }^{1}$ but pose major problems. Only T use for well-documented organic rather than functional hypogonadism can be approved in sport. Problems include a tendency by some doctors to prescribe supplementary $\mathrm{T}$ to treat athletes with low normal serum $\mathrm{T}$, often after inadequate biochemical investigation. This makes any subsequent thorough assessment difficult because of the suppression of endogenous hormone production, including T. It is essential that only replacement and not excessive $\mathrm{T}$ is administered and that TUECs seek the advice of an expert referee, who must be 'blinded' as to the identity of the athlete and his medical advisors. ${ }^{18}$

TUEs for T in two prospective Olympic athletes without testes (one from a congenital and one a surgical cause) were approved during the 1990s, but only one became an Olympic competitor at a later Games. Another older Olympic athlete had been approved to take T, but this was rejected by the TUEC of the IOC because there was no organic reason to justify its use. The only synthetic AAS that can be approved for use is danazol, which is used to treat the rare genetic deficiency of C- 1 esterase inhibitor, which causes hereditary angioneurotic oedema.

\section{Insulin}

Insulin was prohibited in 1998 because athletes without insulindependent diabetes mellitus (IDDM) were misusing it for its 
anabolic and anticatabolic effects. A test to distinguish synthetic from endogenous insulin has become available and is being introduced into laboratories. ${ }^{19}$ Since 2000, TUEs have been approved for IDDM and, at the last five Games (both Summer and Winter), the TUEC of the IOC has observed the prevalence of IDDM in Olympic athletes to be consistently between 1/1000 and $1 / 1500$ athletes.

\section{Human chorionic gonadotrophin}

Human chorionic gonadotrophin (hCG) was prohibited during the 1980s because athletes were administering it to assist in the restoration of endogenous production of $\mathrm{T}$ after misusing AAS. Some athletes were sanctioned for using hCG with and without detection of the concomitant use of an AAS. Importantly, several athletes have had an asymptomatic seminoma diagnosed because of a high hCG concentration in a doping control urine sample, including, nearly 20 years ago, a prospective Olympic hockey player. In another personally encountered instance, the seminoma was eventually located in the mediastinum of a young elite weightlifter. $^{20}$ It is important that anti-doping organisations ensure that any elevated concentration of hCG is not the result of a seminoma. TUEs for hCG are rarely granted in males for proven hypogonadotrophic hypogonadism and for infertility, provided that this is not a consequence of known or suspected previous misuse of AAS.

\section{Conclusion}

Drugs have long been, and will continue to be, a focus of attention at elite sporting competitions, including the Olympic Games. Unfortunately and too often, misuse of prohibited performance-enhancing drugs tends to overshadow the outstanding sporting achievements of clean athletes. Elite athletes, similar to their non- or less athletic counterparts, do experience medical conditions that necessitate treatment with drugs that are prohibited in sport. Fortunately, a tightly regulated process does enable both the therapeutic needs of most of these athletes to be met and for them to participate at the highest levels of sport.

\section{References}

1 Catlin DH, Fitch KD, Ljungqvist A. Medicine and science in the fight against doping in sport. J Intern Med 2008;264:99-114.

2 World Anti-Doping Agency. International standard for therapeutic use exemptions. www.wada-ama.org/Documents/World_Anti-Doping Program/WADP-IS-TUE/2011/WADA_ISTUE_2011_EN.pdf [Accessed 27 March 2012].

3 World Anti-Doping Agency. Additional information in regards to the reintroduction of pseudoephedrine to the 2010 Prohibited List. www. wada-ama.org/Documents/World_Anti-Doping_Program/WADP-
Prohibited-list/WADA_Additional_Info_Pseudoephedrine_2010_ EN.pdf [Accessed 27 March 2012].

4 Kruse P, Ladefoged J, Nielsen U, Paulev P, Sorensen J. $\beta$-blockade used in precision sports - effect in pistol shooting performance. J Appl Physiol 1986;61:417-20.

5 World Anti-Doping Agency. The World Anti-Doping Code: The 2012 Prohibited List.www.wada-ama.org/Documents/World_Anti-Doping Program/WADP-Prohibited-list/2012/WADA_Prohibited_List_2012_ EN.pdf [Accessed 27 March 2012].

6 Duclos M. Glucocorticosteroids: a doping agent? Endocrinol Metab Clin N Am 2010;39:107-26.

7 Arlettaz A, Portier H, Locoq AM et al. Short term glucocorticosteroid intake improves exercise endurance in healthy recreationally trained women. Eur J Appl Physiol 2009;107:437-43.

8 Ekblom B, Goldbarg AN, Gullbring B. Response to exercise after blood loss and reinfusion. J Appl Physiol 1972;33:175-80.

9 Brien AJ, Simon TL. The effects of red cell infusion on 10-km race time. JAMA 1987;257:2761-5.

10 Ekblom B, Berglund B. Effect of erythropoietin administration on aerobic power. Scand J Med Sci Sports 1991;1:88-93.

11 Fitch KD. Androgenic-anabolic steroids and the Olympic Games. Asian $J$ Androl 2008;10:384-90.

12 Silvester J. Anabolic steroids at the 1972 Olympic Games. Scholastic Coach 1973;43:90-2.

13 Franke WW, Berendonk B. Hormonal doping and androgenization of athletes: a secret program of the German Democratic Republic Government. Clin Chem 1997;43:1262-79.

14 Brooks RV, Firth RG, Sumner NA. Detection of anabolic steroids by radio-immunoassay. Br J Sports Med 1975;9:89-92.

15 Bhasin S, Storer TW, Berman N et al. The effects of supraphysiologic doses of testosterone on muscle size and strength in normal men. $N$ Engl J Med 1996;335:1-7.

16 Strahm E, Scottas PE, Schweizer C et al. Steroid profiles in professional soccer players; an international comparative study. Br J Sports Med 2009;43:1126-30.

17 Aguilera R, Chapman TE, Starcevic B et al. Performance characteristics of a carbon isotope ratio method for detecting doping with testosterone based on urine diols: controls and athletes with elevated testosterone/epitestosterone ratios. Clin Chem 2001;47:292-300.

18 World Anti-Doping Agency. Medical information to support decisions of TUECs -Androgen Deficiency/Male Hypogonadism. www.wada-ama. org/Documents/Science_Medicine/Medical_info_to_support_TUECs/ WADA-Medical-info-Androgen-Def-Hypogonadism-2.0-EN.pdf [Accessed 27 March 2012].

19 Thevis M, Thomas A, Schänzer W. Insulin. Handb Exp Pharmacol 2010;195:209-26.

20 Newcomb AE, Clarke CP, Chiang CY, Jerums G. Urine drug testing in an athlete leads to the diagnosis of unsuspected mediastinal germ cell tumour. J Thorac Cardiovasc Surg 2006;132:722-3.

Address for correspondence: Prof Ken Fitch, School of Sports Science, Exercise and Health, M408, Faculty of Life Sciences, University of Western Australia, Crawley 6009 Western Australia, Australia.

Email: ken.fitch@uwa.edu.au 